\title{
A REGULAÇÃO DE INVESTIMENTO ENTRE BRASIL E ANGOLA: CONDICIONANTES INTERNOS, CONTEXTO INTERNACIONAL E A CONSTRUÇÃO DO ACORDO DE COOPERAC̣ÃO E FACILITAC̣ÃO DE INVESTIMENTOS (ACFI)
}

\author{
Michelle Ratton Sanchez Badin ${ }^{1}$ \\ Fabio Morosini ${ }^{2}$ \\ Ely Caetano Xavier Junior ${ }^{3}$
}

\section{Introdução}

O objetivo deste artigo é contextualizar o cenário regulatório relativo a investimentos estrangeiros, na Angola e no Brasil, em seus movimentos individuais e conjuntos. Essa análise resulta da pesquisa "Evidências empíricas sobre a regulação do Comércio Internacional e do Investimento Estrangeiro em Perspectiva Brasileira: o caso de Angola"4, que procura identificar as bases

\footnotetext{
I Professora associada na Escola de Direito de São Paulo da Fundação Getulio Vargas. E-mail: michelle.sanchez@fgv.br

2 Professor da Faculdade de Direito da Universidade Federal do Rio Grande do Sul (UFRGS). Ph.D. e mestre em Direito Internacional pela University of Texas at Austin. E-mail:

fabio.morosini@gmail.com

3 Professor de Direito Internacional da Universidade Federal Rural do Rio de Janeiro (UFRRJ). Doutorando em Direito Internacional pela Faculdade de Direito da Universidade de São Paulo (USP). E-mail: exavier@ufrrj.br

4 Este projeto conta com financiamento das seguintes agências de financiamento à pesquisa: Coordenação de Aperfeiçoamento de Pessoal de Nível Superior e Conselho Nacional de Desenvolvimento Científico e Tecnológico (MCTI/CNPq/MEC/CAPES n. 43/2013) e Fundação de Amparo à Pesquisa do Estado de São Paulo (Processo FAPESP 20I4/25776). Estão filiados a este projeto mais de vinte pesquisadores, aos quais agradecemos pela contribuição com suas
} 
regulatórias das relações econômicas entre Angola e Brasil, sob o argumento de um eixo de cooperação Sul-Sul.

Angola e Brasil são países classificados em diferentes escalas de desenvolvimento econômico e social, porém com um histórico de aproximações política e econômica valorizado pela política externa de ambos os países. Um movimento similar pode ser observado no que diz respeito à regulamentação dos investimentos estrangeiros em tais países: posições e regulamentações domésticas distintas, porém um esforço de regular as relações bilaterais a partir de um eixo comum de concessões. Buscamos, assim, realizar uma análise comparativa entre os movimentos paralelos de regulação dos investimentos estrangeiros em Angola e Brasil, argumentando que a divergências de posicionamento desses países - em relação tanto aos acordos internacionais de investimento (AAIs) quanto às reformas legislativas internas - parecem ter se reconciliado na assinatura do Acordo de Cooperação e Facilitação de Investimentos (ACFI), em abril de 2015.

O artigo está estruturado em quatro outras seções, além desta introdução e da conclusão. Na segunda seção do artigo, apresentamos algumas informações básicas sobre o investimento estrangeiro e sua regulamentação em Angola e Brasil, assim como uma contextualização do histórico do regime internacional de investimentos, com o propósito de situar o leitor no espaço e no tempo que determinam algumas semelhanças mas muitas diferenças entre os dois países. Na terceira seção, sobre a regulação dos investimentos estrangeiros na Angola e no Brasil, apresentamos um movimento divergente na abordagem dos Acordos de Promoção e Proteção Recíproca de Investimentos (APPIs) por esses países, durante os anos I990 e início dos 2000 . Essa divergência também se refletiu - como discutiremos na quarta seção - nas alterações legislativas internas realizadas por Angola e Brasil, durante a primeira década dos anos 2000. Na quinta seção, por fim, analisamos como os posicionamentos desses países passaram a incorporar uma crítica ao regime dos investimentos estrangeiros e acabaram por se reconciliar com a assinatura do ACFI, no início de 2015 .

pesquisas individuais e com a construção coletiva das chaves de análise. Neste texto especificamente, agradecemos a Rafael Chaves Fonseca que ajudou com a coleta de alguns materiais e em seu trabalho de conclusão de curso fez a análise da regulamentação angolana em investimento (Fonseca 20I5). 


\section{Contexto: o significado dos investimentos estrangeiros para Angola e Brasil}

\section{Breve histórico}

Angola e Brasil celebraram, em novembro de 20I5, os quarenta anos de suas relações diplomáticas. O fato de o Brasil ter sido o primeiro país a reconhecer a independência de Angola, em I975, é um marco no discurso de ressignificação da política externa bilateral, de ambos os países, que compartilharam de um passado colonial comum, tendo Portugal como metrópole. Os processos de colonização por Portugal se mostraram, entretanto, distintos em ambos os países e determinaram ciclos específicos em suas histórias de reestruturação econômica.

Brasil, por um lado, foi sede da Coroa Portuguesa e, tendo sido alçado à condição de reino unido com a metrópole, logrou sua independência em I882. Na sequência, Brasil passou por um período imperial e, ainda no século XIX, converteu-se em uma república. No Brasil, durante o Império e após sua independência, sempre se reconheceu a livre iniciativa e o direito da propriedade privada ${ }^{5}$, ainda que a discriminação entre capital estrangeiro e capital nacional tenha variado conforme o período da história e o setor.

Angola, por outro lado, pelo fato de ter permanecido como colônia durante a fase do neocolonialismo até I975, sua independência se deu num contexto de Guerra Fria e reverberou suas polaridades. Nos primeiros anos após a declaração de sua independência, Angola decidiu implementar uma economia socialista - o que levou inclusive à nacionalização e ao confisco de uma série de investimentos estrangeiros à época. Tal processo foi, contudo, marcado por alguns anacronismos, inclusive na sua relação com o capital estrangeiro. Na I República (I975-I99I) conviveram o resguardo à propriedade privada, mesmo de estrangeiros (art. Io, Lei Constitucional de I970), a Lei 3/76 que previa uma "economia de resistência" e a apropriação pelo estado dos bens de produção, e a Lei ıo/79, do Investimento Estrangeiro, prevendo a associação necessária entre o capital nacional e o estrangeiro ${ }^{6}$. Entre i979 e

5 E.g. já na Constituição Política do Império do Brasil de ı824, art. I79.XXII: "XXII. É garantido o Direito de Propriedade em toda a sua plenitude. Se o bem publico legalmente verificado exigir o uso, e emprego da Propriedade do Cidadão, será elle préviamente indemnisado do valor della. A Lei marcará os casos, em que terá logar esta unica excepção, e dará as regras para se determinar a indemnisação."

6 De acordo com Manuel Ennes Ferreira: “Essas asserções apresentaram-se claramente como contraditórias, paradoxais e até mesmo absurdas. Contraditórias, porque, ao quererem banir, na prática, a actividade industrial privada (...) entram em contradição com a Constituição (...). 
2002, Angola mergulhou em intensa guerra civil e degradação da sua economia. Tal situação favoreceu reformas gradativas no seu regime econômico até o processo de abertura, iniciado em I985, incorporado no Programa de Saneamento Económico e Financeiro (SEF) em i988 e, finalmente, consolidado na reforma da Lei Constitucional em maio de I99I

Para o Brasil, o capital estrangeiro sempre esteve presente e com participação relevante no produto interno bruto ${ }^{8}$. Se, num primeiro momento (especialmente durante o século XIX até I930), o investimento estrangeiro assumia um papel relevante para a participação do Brasil no comércio internacional, a partir dos anos I940 há uma clara política de inserção brasileira no processo de industrialização, voltando-se para política de emprego e transferência de tecnologia. Observa-se, ainda, que as medidas brasileiras para promoção e proteção do investimento estrangeiro, até I990, foram essencialmente adotadas por legislação interna e, portanto, unilateral pelo Brasil9 e ro.

Paradoxais, porque numa altura em que o país necessitava de recuperar a sua economia se levantaram obstáculos ao funcionamento do sector privado. Absurdas, porque (...), em I979, havia sido publicada a Lei do Investimento Estrangeiro (...)." (Ferreira 2002, 50). O angolano Carlos Teixeira qualifica esta fase com "uma presença quase incontornável do Estado na Economia, bastante administrativa, com barreiras burocráticas e planos rígidos" (Teixeira 20II).

7 Catarina Antunes Gomes faz uma análise detalhada sobre esse processo de abertura econômica na Angola, seus determinantes internos e externos (Gomes 2009). A autora alega que a dependência da economia angolana do petróleo prejudicou a organização de uma economia centralizada (p. 233) e que a crise internacional do petróleo levou a uma dura crise financeira da Angola que ao recorrer às instituições financeiras multilaterais, passou a estar sujeita às suas condicionalidades (p. 236 e ss.). E, retrata essa situação com a citação Ennes Ferreira, que qualificaria “o SEF como uma 'Carta de Intenções' dirigida ao FMI e ao Banco Mundial aos quais, aliás, o governo desde logo manifestou o seu interesse em aderir” (Ennes Ferreira I993, 13-4 apud Gomes 2009, 239).

8 Para os casos de Angola e Brasil, é muito difícil conseguir dados sobre investimentos precisos e fundados em metodologias similares em períodos anteriores a I990, momento em que a base da UNCTAD passou a padronizar e sistematizar os dados de investimento (http://unctad. org/en/Pages/Statistics.aspx). No caso do Brasil, algumas referências da literatura reforçam a percepção da continuidade da importância do investimento estrangeiro e da sua relação com projetos de desenvolvimento nacional, e.g. (Gonçalves I999) (ver especificamente pp. 236-46), (Almeida 2003), (Caputo e Melo 2009).

9 A única exceção a esta regra foi Acordo de Garantia de Investimento assinado entre Brasil e Estados Unidos, nos anos I960, publicado pelo Decreto n. 57.943, de io de março de i966. Sobre as particularidades deste acordo e seus diferenciais quanto ao um acordo tradicional de promoção e proteção de investimentos, v. Nusdeo 2007.

Io Sobre a exemplificação de medidas unilaterais do Brasil, por meio de legislações específicas, seja na área comercial, bancária, cambial ou securitária, v. (Almeida 2003), (Gonçalves I999) e (Caputo e Melo 2009). A legislação mais específica, nesse conjunto, é a Lei n 4 .I3I, de 3 de setembro de I962, modificada pela Lei $\mathrm{n}^{\circ} 4.390$, de 29 de agosto de I964. Na época de sua elaboração, a Lei $n^{\circ} 4.13 \mathrm{I} / 62$ tinha como objetivo garantir a segurança do capital estrangeiro, asse- 
Isso favoreceu a retomada posterior do perfil regulatório do Brasil por meio de medidas internas, como será apresentado na seção 4 a seguir.

Diferentemente, Angola, quase quinze anos após sua independência, reorganizou-se em torno da economia de mercado, incluindo a abertura para o capital estrangeiro, no fim dos anos i980 e início de i990. Isso fez com que a pressão internacional para a adoção de padrões internacionais de promoção e proteção preponderassem para uma efetiva atração do capital estrangeiro ${ }^{\text {II }}$. Mas, considerando o seu histórico de economia planejada para economia de mercado, é também notório o quanto o regime do capital estrangeiro sempre contou com uma série de controles administrativos e condicionalidades, previstos em sua legislação interna.

A partir de 2002, com a Lei n. 05/02 sobre Delimitação dos Sectores de Actividade Económica, Angola consolidou três regimes gerais de investimento, com base em setores: (i) reservados para atuação exclusiva do governo Angolano (artigos II e I2, reserva absoluta ou de controle); (ii) aqueles de propriedade exclusiva do estado, mas que podem ser explorados mediante contrato de concessão (artigo I3, reserva relativa) - entre outros, exploração de petróleo e diamantes que possuem tratamento específico pela legislação Angolana; e (iii) demais, com a indicação em lei dos setores e regiões prioritárias para o investimento privado, que podem receber benefícios fiscais ${ }^{12}$. Em relação a esse último, resguarda-se a livre iniciativa, sendo que, no caso de investimento estrangeiro, em alguns setores se exige parceria com empresa Angolana (artigo $9^{\circ}$, Lei $\mathrm{n}^{\circ}$ I4/15). Suspeita-se, assim, que a atração do capital estrangeiro para Angola tenha objetivado tanto sua inserção no comércio

gurar tratamento não discriminatório ao investidor não residente, atrair e estimular o ingresso de investimentos no país e defender os interesses nacionais, cf. (Dias 20IO, 82). Para acesso à íntegra, v. Lei $\mathrm{n}^{\circ}$ 4.I3I, de 3 de setembro de I962. Disciplina a aplicação do capital estrangeiro e as remessas de valores para o exterior e dá outras providências (Brasil I962).

II Vale notar que a relação histórica da Angola com o capital estrangeiro acabou se construído, na I República, a partir de um regime de exceção, garantindo ao investidor estrangeiro posições e direitos que não eram sequer pensados para o agente privado nacional. Isso fez com que a Lei do Investimento Estrangeiro, em suas diferentes edições, tenha assumido um papel para além de instrumento de garantia quanto a instabilidades locais, incorporando direitos excepcionais ao regime jurídico geral. De tal sorte a legislação de investimento estrangeiro se delineou num extenso estatuto legal, com direitos e deveres ao investidor e com dispositivos sobre questões cambiais, societárias, sobre cessão e sucessão de direitos, tributárias, penais, administrativas (quanto ao funcionamento das agências do estado). Isso, ou ao menos vestígios disso, pode ser observado nas várias leis editadas para o investimento na Angola: Lei $\mathrm{n}^{\circ}$ 10/79, Lei $\mathrm{n}^{\circ}$ 13/88, Lei $n^{\circ}$ I5/94, Lei ${ }^{\circ}$ II/O3, Lei n ${ }^{\circ}$ O/II e Lei ${ }^{\circ}$ I4/15. Para uma apresentação desses regimes até 2003 , v. (UNCTAD 20I0).

I2 Sobre a atual regulamentação dos benefícios fiscais e seus escalonamentos, v. Lei n. I4/I5, de ir de agosto (Anexo). 
internacional - notório nos casos das indústrias do petróleo e de diamantes como o desenvolvimento industrial local - resultante de uma combinação de resquícios do controle anterior típico de uma economia planejada com iniciativas mais contemporâneas que visam a integrar o investimento em políticas de desenvolvimento nacional' ${ }^{13}$.

\section{Panorama internacional}

A regulação dos investimentos estrangeiros passou a ganhar notoriedade na estrutura de acordos internacionais em I950. A UNCTAD, recentemente, sistematizou uma linha de evolução histórica desse AIIs em quatro períodos: (i) I950-1964, surgimento dos acordos; (ii) I965-1989, dicotomia entre proteção e responsabilização dos investidores; (iii) I990-2007, proliferação dos acordos; e (iv) 2008 até hoje, re-orientação de políticas, com denúncias e revisões dos AIIs (Unctad 20I5, I2I).

Os quatro momentos podem ser lidos como processos cíclicos. Se, no primeiro momento (I950-I964), predominava o interesse de países exportadores de capital em criar regras protetivas dos seus investimentos nas novas economias de risco político variável, a segunda fase (1965-1989) orientou-se por um movimento contrário no âmbito da Assembleia Geral da Organização das Nações Unidas, por países receptores que demandavam o respeito à soberania dos seus recursos naturais e o estabelecimento de uma Nova Ordem Econômica Internacional ${ }^{\mathrm{I}}$. Como apresentado acima, Angola e Brasil não aderiram ao primeiro movimento: Angola ainda era colônia de Portugal e o Brasil, por sua vez, reagia com medidas unilaterais para promoção e algumas garantias ao investimento estrangeiro.

A fase seguinte do desenvolvimento dos AIIs (I990-2007), foi im-

I3 Essa é uma percepção a partir da leitura de (Gomes 2009), assim como da exposição de motivos da Lei n. I4/I5, de II de agosto. Como parte desta exposição de motivos, destacamos: "O investimento privado, a par de investimento público, continua a ser uma aposta estratégica do Estado, para a captação e mobilização de recursos humanos, financeiros, materiais e tecnológicos, com vista ao desenvolvimento econômico e social do País, à diversificação da economia, ao aumento da competitividade da economia, ao crescimento da oferta de emprego è à melhoria das condições de vida das populações" (grifo nosso).

I4 Esses primeiros momentos estão intimamente relacionados ao processo de descolonização de grande parte dos atuais países do continente africano e da Ásia e seu posterior alinhamento contestando o regime opressor do sistema econômico internacional. Sobre suas manifestações no âmbito da ONU, v. especialmente Resoluções da Assembleia Geral da ONU n. I.803/1962 e n. 3.20I/I974. O acesso a tais documentos pode ser obtido em <http://www.un.org/en/sections/documents/general-assembly-resolutions/index.html> (última consulta em dezembro de 20I5). 
pulsionada por movimentos de liberalização econômica e globalização. De um total de 404 AIIs correspondentes às fases anteriores, neste período, registraram-se 2.663 novos AIIs, fossem esses acordos de caráter bi-, pluri- ou multilateral ${ }^{15}$. Considerando a proposta de promoção de investimento, esses acordos passaram a ser questionados sobre sua efetividade e, no tocante à proteção do investimento estrangeiro, as regras dos AIIs foram associadas a uma redução de espaço regulatório de políticas públicas e a uma forte exposição aos mecanismos de solução de controvérsias investidor-Estado. Tal contestação caracteriza o quarto período, a partir de 2008 , que tem gerado tanto reformas pontuais às regras existentes, quanto a denúncia dos AIIs pelos países receptores de capital.

Angola e Brasil integraram estes dois últimos movimentos na regulação internacional dos investimentos estrangeiros, associando suas políticas de desenvolvimento ao processo de atração desses investimentos. Tanto Angola como Brasil assinaram os AIIs no formato de Acordos de Promoção e Proteção Recíproca de Investimentos (APPIs), nos anos I990 e Angola também na primeira década dos anos 2000; mas, assim como outros países receptores de capital, revisaram suas políticas nos últimos anos, apresentando uma postura mais proativa na definição de seus compromissos. Esses pontos serão analisados nas seções 3 e 4 a seguir.

\section{Respostas à proliferação da regulação dos investimentos es- trangeiros}

\section{Brasil e os APPIs (1994-1998)}

O Brasil, nos anos I990, assinou um total de catorze APPIs ${ }^{16}$. Pou-

I5 No tocante a essa diversidade de arranjos, são exemplos notórios (i) a criação, em I994, da Organização Mundial do Comércio, contendo regras aplicáveis a investimentos estrangeiros em alguns de seus acordos; (ii) a conclusão da Carta de Energia (Energy Charter Treaty), com disposições detalhadas sobre investimentos neste setor, entre os seus membros; e (iii) a conclusão, em I992, do Acordo Norte-Americano de Livre Comércio (NAFTA, sigla em inglês), que, inter alia, cria regras específicas para investimento estrangeiro e submete suas disputas ao sistema de solução de controvérsias investidor-Estado. Para mais esclarecimentos a respeito desses sistemas, no contexto dos AIIs, v. (Unctad 20I5, I26).

I6 Os APPIs foram assinados com Chile (I994), Portugal (I994), Reino Unido (I994), Suíça (I994), Alemanha (I995), Coréia do Sul (1995), Dinamarca (1995), Finlândia (1995), França (I995), Itália (I995), Venezuela (I995), Cuba (I997), Países Baixos (I998) e Bélgica/Luxemburgo (I999). A íntegra dos APPIs assinados estão acessíveis na base de dados do Sistema de Atos Internacionais do Ministério das Relações Exteriores (<dai-mre.serpro.gov.br $>$, último acesso em dezembro de 20I5). 
co antes do início deste processo, a Constituição Federal aprovada em I988, no capítulo sobre a ordem econômica e financeira determinava que "a lei disciplinará, com base no interesse nacional, os investimentos de capital estrangeiro, incentivará os reinvestimentos e regulará a remessa de lucros" (artigo I72). Contudo, nos anos posteriores, não foi editada nenhuma outra lei sobre investimentos estrangeiros, permanecendo em vigor o regime anterior instituído pela Lei $\mathrm{n}^{\circ}$ 4.I3I/62. Os APPIs seguiram, na época, a orientação de uma minuta-padrão proposta por um Grupo de Trabalho Interministerial, criado em I992 e composto por representantes do Ministério das Relações Exteriores e do então Ministério da Economia, Fazenda e Planejamento ${ }^{17}$. Texto esse que foi, posteriormente, "adaptado a padrões mais realistas, os mais próximos possíveis dos recomendados pela Organização para a Cooperação e o Desenvolvimento Econômico (OCDE)"18.

Apesar disto, semelhanças estruturais e substanciais dos APPIs assinados pelo Brasil prevaleceram. Em todos os acordos assinados estavam presentes dispositivos quase idênticos sobre: (i) definições de investimento, investidor e território, (ii) admissão de investimentos, (iii) promoção dos investimentos, (iv) padrões de proteção dos investimentos, (v) nacionalização, expropriação e indenização, (vi) livre transferência e repatriação dos investimentos, (vii) solução de controvérsias entre Estados partes, (vii) solução de controvérsias entre investidores e Estados, e (viii) vigência e denúncia do tratado.

Dos quatorze APPIs assinados, seis - quais sejam, os acordos celebrados com Alemanha, Chile, França, Portugal, Reino Unido e Suíça - foram encaminhados por mensagens do Presidente da República para ratificação pelo Congresso Nacional ${ }^{\text {I9 }}$, onde enfrentaram resistências no processo de ratificação ${ }^{20}$.

A Comissão de Relações Exteriores e de Defesa Nacional (CREDN) da Câmara dos Deputados, no processo do APPI com o Reino Unido apontou dois pontos controversos que se tornaram centrais no debate nacional. O primeiro ponto era referente à compensação por expropriação: a Constitu-

I7 Cf. Mensagem n ${ }^{\circ}$ I.I58, de I5 de dezembro de I994, que submetia o acordo celebrado com Portugal à apreciação do Poder Legislativo.

I8 Cf. Mensagem $n^{\circ} 8$, de 5 de janeiro de I995, que encaminhou ao Congresso Nacional o acordo celebrado com o Reino Unido.

I9 Os projetos de decreto legislativo eram os seguintes: PDC n ${ }^{\circ} 396 / 00$ (Alemanha), PDC $n^{\circ}$ 366/96 (Chile), PDC n 395/00 (França), PDC n 365/96 (Portugal), PDC n 367/96 (Reino Unido) e PDC n ${ }^{\circ} 348 / 96$ (Suíça).

20 Sobre esses processos e as particularidades do debate em suas tramitações, v. (Scandiucci Filho 2007) 
ição Federal admite seu pagamento em títulos da dívida pública ou em títulos da reforma agrária, o que poderia contrastar com o compromisso de livre e pronta transferência de recursos, independentemente da disponibilidade de divisas pelo país ${ }^{21}$. Se fosse garantida exceção ao preceito constitucional ao investidor estrangeiro, isso configuraria um tratamento diferenciado desse em relação àquele dispensado ao investidor nacional.

Em relação à previsão de solução de controvérsias entre Estado e investidor, o parecer da CREDN da Câmara dos Deputados alegava que tal dispositivo violaria "regra de direito internacional consuetudinário tradicionalmente adotada pelo Brasil, o princípio do esgotamento de recursos internos" (Brasil 2000, 21.693). Ademais, o acesso direto do investidor estrangeiro à arbitragem internacional colocaria o particular em igualdade com o Estado brasileiro, o que representaria uma "proteção de investidores internacionais em detrimento de políticas e interesses nacionais" (Alves 20I4). De maneira semelhante, foi criticada no parecer parlamentar a possibilidade de alteração do foro no decorrer do processo, por escolha do investidor, alertando-se que, em função da cláusula da nação favorecida, a mesma prerrogativa poderia ser estendida, independentemente de previsão expressa, a outros países com os quais o Brasil viesse a celebrar APPIs (Brasil 2000, 21.693).

Algumas das críticas dirigidas aos APPIs assinados pelo Brasil acabaram, assim, por dar margem à proposição de emendas pelos parlamentares ${ }^{22}$ e, mais à frente, levaram à retirada pelo próprio Poder Executivo dos projetos de ratificação dos APPIs da tramitação na Câmara dos Deputados ${ }^{23}$. Além de

2I De acordo com a manifestação parlamentar, a "forma de indenização definida no texto precisa ser confrontada com alguns dos preceitos constitucionais vigentes acerca da desapropriação de imóveis urbanos e rurais". Além de estabelecer o pagamento da indenização pela expropriação de terras para fins da reforma agrária em moeda conversível, quando o pagamento realizado, na mesma hipótese, seria em títulos da divida agrária resgatáveis em até vinte anos (Brasil 2000, 21.693).

22 Por exemplo, as emendas propostas ao projeto de decreto legislativo que aprovaria o texto do acordo celebrado com a Alemanha. O projeto de decreto legislativo continha os seguintes dispositivos: "Art. $2^{\circ} \mathrm{O}$ disposto no $\int 2^{\circ}$ do art. $4^{\circ}$ do Acordo [sobre expropriação] somente será aplicado no que não contrariar os casos previstos na Constituição Federal, especialmente o inciso III do $\int 4^{\circ}$ do art. I82, e o art. I84. Art. $3^{\circ}$ A expressão "a pedido do investidor", contida no art. Io do Acordo [sobre solução de controvérsias entre Estado e investidor], é interpretada no sentido de que o recurso à arbitragem internacional depende, necessariamente, da anuência do Governo brasileiro, quando os investimentos forem realizados em território nacional. Art. $4^{\circ}$ Os compromissos assumidos neste Acordo terão que se submeter à regulamentação prevista no art. I72 da Constituição Federal”. (Brasil 2003, 37795-6).

23 A decisão de retirar os APPIs da tramitação no Congresso Nacional decorreu de proposta formulada pela comissão instituída em 2002, durante a transição presidencial entre Fernando Henrique Cardoso e Luiz Inácio Lula da Silva, para avaliar os APPIs pelo país (Alves 20I4, 423-46). 
registrar a percepção de que os APPIs concediam um "conjunto demasiado abrangente de direitos e prerrogativas" aos investidores estrangeiros, os documentos do Poder Executivo ${ }^{24}$ apresentavam o argumento da desnecessidade dos acordos para o Brasil, que mantinha sua posição de destino privilegiado de capitais estrangeiros ${ }^{25}$.

\section{Angola e os APPIs (1997-2011)}

Angola passou a assinar APPIs a partir de I997, antes mesmo do fim da guerra civil no país (1992-2002). As reformas econômicas internas em Angola, durante os anos I980 e I990, já haviam antecipado alguns elementos dos APPIs em sua legislação nacional. Exemplo disso era a Lei do Investimento Estrangeiro $n^{\circ}$ I3/88 que, na ânsia por atrair capital, havia antecipado garantias para os investidores estrangeiros que dialogavam com as cláusulas de proteção ao investidor nos APPIs, das quais se destacam (i) o tratamento justo e equitativo, (ii) proteção e segurança, com o compromisso de não dificultar a sua gestão, (iii) a transferência para o exterior dos lucros líquidos, mediante autorização do Ministro das Finanças, (iv) a previsão de indenização justa, em caso de expropriação, e (v) a supressão do limite de controle pelos investidores estrangeiros nas empresas Angolanas (Angola I988) ${ }^{26}$. Contudo, como economia planejada, essa legislação ainda previa uma série de condicionalidades e contrapartidas do investidor estrangeiro.

Também no início dos anos I990, Angola acedeu às principais organizações econômicas internacionais - Agência Multilateral de Garantia de Investimentos (1989), Fundo Monetário Internacional (I989, com o estabelecimento de representação em I997) e Organização Mundial do Comércio (I996) - o que fortaleceu a percepção sobre a necessidade de proteção do investidor. E, considerando que a atração de capital ainda se mantinha insatisfatória, em 1994, foi adotada a nova Lei dos Investimentos Estrangeiros $n^{\circ}$

24 "A inexistência de acordos do gênero não tem afetado a posição do Brasil como importante receptor de investimentos internacionais, sobretudo de investimentos diretos, cujos fluxos de entrada encontram-se entre os mais altos no grupo dos países em desenvolvimento. Explicam esse notável desempenho a estabilidade das regras jurídicas no âmbito doméstico e a força intrínseca que a economia brasileira passou a demonstrar a partir de I994." (Brasil 2002, 54.4I4).

25 Vale destacar que, conforme dados da UNCTAD, o Brasil em I994, ano da assinatura do primeiro APPI registrava um influxo de investimento estrangeiro da ordem de US\$ 2,I5 bilhões, e em 2000, este valor tinha atingido a cifra de US\$ I6,6 bilhões (sendo quem em 2000 tinha tido o seu pico em US\$32,8 bilhões) (Unctad s.d.)

26 Comentários sobre os impactos desta Lei são apresentados em (UNCTAD 20I0, 8-II). 
I5/94, com vistas, sobretudo, à redução da burocracia para entrada de capital no país.

Do total de dez APPIs assinados por Angola, oito foram assinados entre 1997 e $2008^{27}$. Assim, em paralelo à assinatura de alguns APPIs durante os anos 2000, Angola buscou, imediatamente depois do fim da guerra civil, modernizar sua legislação relacionada aos investimentos estrangeiros. Nesse sentido, foi adotada a Lei $\mathrm{n}^{\circ}$ II/03, denominada Lei de Bases do Investimento Privado (LIP), que buscava tratar igualmente investimentos privados nacionais e estrangeiros (Angola 2003a). Embora o objetivo da LIP tenha sido tratar mais amplamente de aspectos contratuais, tributários e cambiais relativos aos fluxos de capitais nacionais e estrangeiros, houve uma preocupação específica de incorporar mais algumas das demandas de investidores estrangeiros, normalmente presentes nos APPIs. Nesse sentido, a LIP adota um conceito amplo de investimento estrangeiro, garantindo-lhe, desde que equivalente a montante superior a cem mil dólares (artigo 9.3): (i) tratamento nacional (artigo 4(c)); (ii) tratamento justo e equitativo (artigo I2); (iii) livre acesso aos mercados, exceto em áreas reservadas ao Estado (artigo 4(a)); (iv) proteção e segurança (artigo 4(b)); (v) liberdade de transferência de lucros (artigo I3); (vi) indenização justa, pronta e efetiva nos casos de expropriação por justificado interesse público (artigo I4.2); (vii) acesso aos tribunais Angolanos (artigo I4.I) e recurso à arbitragem realizada em Angola com aplicação da lei Angolana (artigo 33); e (viii) respeito e integral cumprimento dos acordos internacionais (artigo 4(d)). Do ponto de vista do investidor estrangeiro, a LIP obrigava ao cumprimento das leis Angolanas (artigo I7) e à contratação de mão-de-obra Angolana para postos de trabalho e de gestão nos empreendimentos realizados no país (artigos I8 e 54), juntamente com outras obrigações específicas, remanescentes das condicionalidades e contrapartidas da era da economia planejada.

27 Conforme a base da UNCTAD, Angola assinou nove APPIs e outros oito AAIs. Desses nove APPIs, apenas quatro entraram em vigor. Os nove APPIs são: Cabo Verde (assinado e em vigor desde 1997), Itália (assinado em I997, em vigor desde 2007), Portugal (um assinado em I997 e outro, em 2008), Reino Unido (assinado em 2000), Alemanha (assinado em 2003, em vigor desde 2007), África do Sul (assinado em 2005), Espanha (assinado em 2007) e Rússia (assinado em 2009, em vigor desde 20II) v. <http://investmentpolicyhub.unctad. org/IIA/CountryBits/5\#iiaInnerMenu> (último acesso em dezembro de 20I5). Além desses APPIs, tivemos acesso a mais um APPI assinado por Angola com Cuba, versão publicada e em vigor desde I4 de abril de 2009, no Diário da República de Angola I Série, n. 68. Assumimos assim que são dez APPIs assinados por Angola até o momento, estando cinco deles em vigor. A contrario, o último relatório de revisão de políticas comerciais da Angola, pela OMC, indica que são treze APPIs assinados pelo país, sem fazer referência ao acordo com a África do Sul, e incluindo acordos com França, Guiné-Bissau, Holanda, Namíbia e Suíça (WTO 20I5, 26). Não encontramos, no entanto, referências a esses últimos acordos. 
O regime instituído pela Lei $\mathrm{n}^{\circ}$ II/O3 foi complementado pela Lei $\mathrm{n}^{\circ}$ I7/03 que criou as zonas de desenvolvimento, dividindo o território Angolano em três zonas, cujos requisitos quantitativos para investimento, repatriação, concessão de incentivos fiscais e reinvestimento eram distintos, e pelo Decreto $\mathrm{n}^{\circ}$ 44/03 que criou a Agência Nacional para o Investimento Privado (ANIP) com as atribuições de supervisão da política sobre investimentos, gerenciamento dos procedimentos relativos aos fluxos de capitais e autorização da concessão de incentivos para os investimentos (Angola 2003b; Angola 2003C).

A estrutura geral dos dez APPIs assinados por Angola contempla, essencialmente, o seguinte conteúdo: (i) objetivo geral de proteção dos investimentos estrangeiros com a consagração dos padrões de tratamento tracionais, entre os quais de destacam o tratamento nacional, o tratamento da nação mais favorecida e o tratamento justo e equitativo; (ii) definição ampla dos investimentos estrangeiros cobertos; (iii) cláusula geral estabelecendo a proibição de expropriar os investimentos estrangeiros, exceto por interesses públicos, caso em que deverá ser paga indenização e observado o devido processo legal; (iv) previsão de arbitragem ad hoc ou institucional entre investidores e Estado, além da possibilidade de recursos aos tribunais Angolanos e da arbitragem entre Estados.

Observa-se, portanto, que os acordos assinados e ratificados por Angola seguiram, praticamente, o formato geral de APPIs, que também havia sido apresentado ao Brasil. A diferença em relação ao Brasil é que a legislação interna de Angola, desde I988, já dialogava diretamente com a linguagem dos APPIs, em especial no tocante aos dispositivos de proteção do investidor. Por outro lado, é curioso notar que elementos relevantes do regime do investimento estrangeiro em Angola não foram incorporados aos APPIs assinados pelo país. Fazemos referência aqui aos deveres previstos para os investidores, tidos como condicionalidades e contrapartidas do investidor estrangeiro, especificamente (e.g. contratação de mão-de-obra local). A hipótese para essa situação é de que o poder internacional de barganha de Angola era deveras frágil para incorporar tais compromissos na estrutura geral básica dos AP$\mathrm{PIS}^{28}$.

28 Curiosamente essa ressalva também vale para os APPIS assinados entre Angola e Cuba (2008) e entre Angola e Rússia (2009). Em contrário, o APPI Angola-Cuba, assim como aqueles assinados com Alemanha e Itália, possui uma cláusula (art. 20) em que reforça que se a legislação doméstica tiver tratamentos ainda mais favoráveis, eles devem prevalecer. Uma possível interpretação sobre as condicionalidades e contrapartidas da legislação angolana é de que seriam tratamentos mais onerosos aos investidores e, portanto, não seriam exigíveis. 


\section{Gênese da re-orientação}

\section{Reformas na legislação brasileira}

Considerando que o Brasil manteve sua histórica posição de não adesão aos AIIs, o tema, após os anos I990, permaneceu integralmente regulado pela normativa doméstica. Contudo, muitas das demandas encartadas nos APPIs foram incorporadas ao ordenamento jurídico nacional por meio de reformas internas. Lemos e Campello registram, quase que ironicamente, que apenas os dispositivos sobre solução de controvérsias investidor-Estado não foram internalizados (Campello e Lemos 2015, 1078) 29.

De fato, ao longo dos anos I990, como desdobramento do processo de redemocratização, foram realizadas algumas reformas institucionais importantes para o ambiente econômico brasileiro ${ }^{30}$. Trata-se de perceber que essas mudanças não se processaram pela reforma das leis pelo Congresso Nacional, mas por uma atuação regulamentar de alguns órgãos do Poder Executivo (Salama 20I0, I72) 3. $^{\text {I }}$ Além disso, em diversos aspectos pontuais, a mudança de consensos interpretativos dos órgãos encarregados de normatização e supervisão das operações de câmbio contribuíram para a atualização - ainda que com menor grau de segurança jurídica - do ambiente regulatório brasileiro, relativo ao investimento estrangeiro (Salama 20I0, I76).

De maneira mais geral, os desenvolvimentos estruturais da economia brasileira, materializados em fatores como o aumento do volume de negócios na bolsa de valores , a multiplicação de oferta pública inicial de ações (IPOs) , a alteração da legislação contábil com um alinhamento aos padrões internacionais, a minimização dos riscos de investimentos e o aumento de transparência e segurança nas transações empresariais também contribuíram para que o

29 Observa-se que tampouco o Brasil procedeu a alterações relativas às expropriações de investimentos estrangeiros ou a uma atualização do regime de desapropriações, talvez porque o país não tenha se envolvido em um histórico significativo de tomada de propriedade de investidores estrangeiros.

30 Houve uma progressiva liberalização do regime de controle cambial, sobretudo por meio de normas infralegais oriundas do Conselho Monetário Nacional e do Banco Central. Desde o final da década de I990, por exemplo, o ingresso de capitais estrangeiros passou a ser realizado por registro declaratório, prescindindo de qualquer espécie de autorização, nos termos do que dispõe a Resolução CMN nº 3.844/ıo (Brasil 20I0).

3I Nesse sentido, o autor reconhece que, embora se possa dizer que as medidas implementadas pelo Poder Executivo são "mecanismos procedimentalmente complicados e com base legal em alguma medida questionável”, por se tratar de um abuso do poder regulamentar infralegal, acabou por prevalecer a visão de que "a legislação de origem no Congresso de fato abria a possibilidade de que o Poder Executivo implementasse as mudanças que fez” (p. I72). 
país criasse um ambiente econômico e institucional favorável aos investimentos estrangeiros ${ }^{32}$, incorporando algumas das garantias que são - de outros modos - buscadas pelos investidores. De uma maneira geral, essas mudanças regulatórias e institucionais em combinação com a política econômica e a conjuntura internacional fizeram com que o volume de capital estrangeiro recebido pelo Brasil quase que triplicasse, entre 2000 e $2015^{33}$.

A satisfação com as novas cifras de investimentos recebidos, no Brasil, não foram razão para que o assunto de AIIs fosse completamente abandonado no âmbito do estado brasileiro. Após a retirada do APPIs do Congresso Nacional, em 2002, a Câmara de Comércio Exterior (CAMEX) instituiu um grupo de trabalho interministerial, para apresentar opções de encaminhamento à política brasileira sobre a matéria. Nesse momento da história, o Brasil já havia passado a registrar também um número mais significativo de exportação de capitais e se apresentava na agenda nacional o debate sobre a internacionalização de empresas brasileiras ${ }^{34}$. O grupo de trabalho recomendou a renegociação dos acordos com os parceiros estratégicos do Brasil, de maneira que, em agosto de 2005, a CAMEX estabeleceu novo grupo de trabalho interministerial para definir linguagens alternativas para as cláusulas centrais dos AIIs. Outras iniciativas de buscar um modelo alternativo para os acordos de investimento se sucederam nos diferentes órgãos do Poder Executivo, mas as negociações permaneceram sem resultados concretos ao longo de mais de uma década (Brasil 2008, I8-2I).

Foi apenas em 2012 que a CAMEX conferiu um mandato formal para um Grupo Técnico de Estudos Estratégicos de Comércio Exterior (GTEX) explorar, dentre outros tópicos, a elaboração de um novo acordo de investimento sensível às necessidades e limitações brasileiras e aspirações no cenário internacional.

Desde o início do processo negociador, o Brasil vislumbrava um acordo diferente daqueles negociados nos anos I990. Paralelamente a um movimento de contestação internacional contra a assimetria das relações de inves-

32 Dentre alguns dados sobre esses assuntos, cf. sobre o índice da Bolsa de Valores que, após 2005, passou a alcançar patamares entre 33.000-65.000 pontos (http://www.bmfbovespa.com. br); a Comissão de Valores Mobiliários, entre 2004 e 20I3, efetuou o registro de uma média anual de 23 editais de ofertas públicas de ações (http://www.cvm.gov.br). Últimos acessos às páginas eletrônicas em dezembro de 20I5. Sobre a mudanças da legislação, v. (Brasil 2007, 2), (Brasil 20II, 2) e (Brasil 2013, I).

33 Se, em 2000 , o Brasil registrou o influxo de US\$22,5 bilhões, em 2014 esta cifra foi de US\$ 62,5 bilhões (Unctad s.d.)

34 Em 2002, Brasil registrava US\$2,5 bilhões de capital exportado, em contraponto com os US\$624 milhões de I990 (Unctad s.d.). Sobre a internacionalização de empresas brasileiras (Camex et al. 2009). 
timento e as suas regulações, o acordo de investimento desenhado pelo Brasil foi igualmente influenciado pelas lições do processo negociador da década de 1990 e demandas internas por acesso a mercados e alguma proteção dos investidores e investimentos brasileiros. Assim sendo, o GTEX iniciou o processo e consultas com o setor privado a respeito dos principais desafios para a internacionalização das empresas brasileiras - isso culminou na publicação de um relatório ${ }^{35}$. Uma minuta para este acordo, endereçando as demandas do setor privado e posições da política externa brasileira, ficou pronta em 20I3, quando foi aprovada pela CAMEX para posteriores negociações bilaterais.

Dando seguimento à estratégia gestada no GTEX, o MDIC iniciou o processo de apresentar este modelo de acordo para países receptores de investimentos brasileiros, como parte de uma "iniciativa brasileira de estabelecer acordos de investimentos com países dos continentes africano e sul-americano" (Brasil 20I3) ${ }^{36}$. Moçambique e Angola foram os primeiros países a assinarem este novo formato de acordo com o Brasil, seguidos de México, Malauí, Colômbia e Chile, todos em 2015 (Brasil 2015a; Brasil 20I5b).

Os Acordos de Cooperação e Facilitação de Investimentos (ACFIs) negociados até o momento apresentam as seguintes características fundamentais: (i) o desenho da gestão institucional do acordo; (ii) a sistemática para prevenção e resolução de eventuais controvérsias no âmbito do acordo; (iii) as regras de proteção dos investidores estrangeiros, (iv) a incorporação de temas sensíveis no âmbito do acordo, e (v) a inclusão de agendas temáticas, que foram concebidas para ser a parte mais dinâmica dos acordos. Ainda que seja possível identificar uma estrutura padrão para os ACFIs assinados até o momento, reconhecemos que existem variações entre esses acordos, que podem ser explicadas pelas demandas apresentadas pelos diferentes parceiros. Nossa análise, a partir da seção 5, focará nas peculiaridades do acordo de investimento com Angola.

\section{Reformas na legislação Angolana}

Na trajetória de Angola, o processo de re-orientação foi uma combi-

35 As consultas com o setor privado envolveram a Federação das Indústrias do Estado de São Paulo (FIESP) e a Confederação Nacional da Indústria (CNI). Os resultados foram em grande medida consolidados no relatório (CNI 2013). Descrevemos um pouco mais deste processo em outro artigo (Morosini e Sanchez Badin 2015).

36 De acordo com as informações do Secretário de Comércio Exterior, "estes acordos que estamos buscando seriam instrumentos de apoio para os investidores brasileiros atuarem no exterior. Estamos propondo tratar de temas relevantes e práticos, do dia a dia, como concessão de vistos e outros que afetam o processo de decisão sobre o investimento". 
nação de novas reformas na sua lei de investimento, a continuidade de negociação de APPIs tradicionais e a procura por padrões próprios para os AIIs. Angola, diferentemente do Brasil, desde 2005, tem apresentado cifras de desinvestimento no país e um aumento da sua própria exportação de capital37. Esses dados de alguma forma indicam algumas das preocupações do país em suas reformas legislativas e que levaram à adoção da Lei do Investimento Privado $\mathrm{n}^{\circ}$ 20/II, recentemente substituída pela Lei $\mathrm{n}^{\circ}$ I4/15.

A Lei $\mathrm{n}^{\circ}$ 20/II trouxe algumas inovações significativas para o regime dos investimentos estrangeiros em Angola. Se a Lei anterior ( $\mathrm{n}^{\circ}$ II/03) procurava maximizar a atração de investimentos para um país que havia recentemente saído de uma guerra civil, a filosofia de Lei $\mathrm{n}^{\circ} 20 /$ II foi colocar o investimento a serviço do desenvolvimento Angolano, de maneira a atrair investimentos estrangeiros de maior volume, preferencialmente para áreas estratégicas definidas. Por isso, foi uma das mais extensas leis sobre investimento, prevendo inúmeros detalhes sobre compromissos e procedimentos dos investidores. Por tal razão, a LIP de 20 II estabeleceu o princípio da conformação política e legal e passou a exigir a aprovação prévia de todos projetos de investimento pela Agência Nacional para o Investimento Privado (ANIP) (artigo 52), extinguindo o regime de aprovação tácita existente na lei anterior. Complementarmente, mas também como eco do movimento internacional de contestação dos APPIs, uma alteração importante foi a supressão da cláusula proibitiva de expropriação (artigo I4 da Lei nº3/II, em contraponto com artigo $\mathrm{I} 6$ da Lei $\mathrm{n}^{\circ}$ 20/II).

Em paralelo à reforma na LIP, Angola aprovou, em I994, um paradigma para os APPIs, com o objetivo de instituir um modelo de acordo a ser utilizado por Angola nas negociações com outros países. É interessante notar que o Paradigma de Investimentos (Angola 20I4) tem como traço característico a referência ao direito nacional dos Estados contratantes para fins - por exemplo - de (i) definição de investidor e investimentos (artigos I.2 e 2); (ii) política de admissão de investimentos estrangeiros (artigo 3.I); (iii) determinação de áreas reservadas ao Estado (artigo 3.2) e (iv) transferência de recursos (artigo 7). Além disso, a concessão do tratamento justo e equitativo e a garantia de proteção e segurança estão condiciondos às "realidades sociais" dos Estados contratantes (artigo 4.I).

Em relação às garantias ao investidor, o Paradigma de Investimentos manteve (i) a proibição de medidas arbitrárias (artigo 4.2); (ii) a observância

37 Se em 2003, no ano de aprovação da Lei II/03, Angola registrava o influxo de investimento estrangeiro da ordem de US\$3,6 bilhões, em 20II, ano da nova alteração legislativa havia um registro negativo, de desinvestimento, em torno de -US\$3 bilhões. Esse número praticamente se manteve em 2014 (Unctad s.d.). 
de obrigações que o Estado tenha assumido expressamente perante o investidor (artigo 4.3); (iii) o tratamento da nação mais favorecida (artigo 4.4); (iv) o tratamento nacional (artigo 4.8); e (v) o pagamento de indenização justa, adequada e efetiva, nos casos de expropriação por interesse público e não-discriminatória, com possibilidade de recurso aos tribunais nacionais da parte que realiza a expropriação (artigo 5). Quanto às obrigações do investidor, o Paradigma de Investimentos determina que "o investimento deve focalizar a proteção do meio ambiente e do desenvolvimento sustentável” (artigo I0.2), além de "promover o recrutamento de força de trabalho nacional" (artigo I0.3).

Outro movimento do Paradigma de Investimento a destacar foi sobre o sistema de solução de controvérsias, que difere daqueles previstos nos APPIs assinados por Angola. Em relação às controvérsias entre investidores e Estados, o Paradigma de Investimentos veda, expressamente, o recurso à arbitragem internacional, determinando que as controvérsias sejam resolvidas "nos termos das respectivas legislações nacionais" (artigo I4.5). Em relação às controvérsias entre Estados são previstas consultas e negociações, com a eventual participação do setor privado (artigos I4.I a I4.3), que, se infrutíferas, podem ser levadas à Corte Internacional de Justiça (artigo 14.4).

Em certa medida, o Paradigma de Investimentos buscou reproduzir algumas das diretrizes existentes nas leis internas Angolanas, inclusive pela remissão direta a elas. Traços distintivos da lei Angolana - como a necessidade de contratação de mão-de-obra nacional - encontraram finalmente eco no modelo de acordo internacional de Angola. Por sua vez, o paradigma também reverte muitas das concessões tradicionais de APPIs, que em momentos anteriores da história até mesmo já haviam sido integrados na LIP Angolana.

Por fim, dentre os mais recentes movimentos legislativos em Angola, temos a Lei $\mathrm{n}^{\circ} \mathrm{I} 4 / \mathrm{I} 5$, de II de agosto. Essa é a nova LIP que veio a reforçar as propostas anteriores de associar a regulamentação dos investimentos "ao desenvolvimento económico e social do País, à diversificação da economia, ao crescimento da oferta de emprego e à melhoria das condições de vida da população" (exposição de motivos). Imbuída desse espírito a Lei n ${ }^{\circ}$ I4/I5 eliminou de seu texto o princípio geral de tratamento nacional e de respeito e integral cumprimento dos AIIs. A nova LIP também associa os incentivos e aprovações de investimento aos projetos previstos para as zonas econômicas e especiais, zonas francas e os polos de desenvolvimento no país (artigos $35 \mathrm{e}$ segs.) - parte de um projeto nacional de desenvolvimento industrial e regional. Por meio desta lei foi extinta a ANIP que será substituída por outro órgão, em futuro próximo.

Observa-se que reações ao regime internacional de investimentos são 
bastante recentes e, portanto, com pouco tempo hábil para entender o impacto que terão no capital estrangeiro em Angola, bem como para a sua exportação de capital para outros países. Após todas estas alterações em sua legislação interna Angola não assinou nenhum novo APPI. O único novo acordo de investimento assinado foi aquele com o Brasil, que partiu da proposta inicial do ACFI estruturado no âmbito do governo brasileiro. Por isso, a análise do acordo assinado entre Angola e Brasil pode ser um teste interessante para verificar o alinhamento de propostas ou as concessões que pesaram para cada uma das partes, em nome do interesse da aproximação político-econômica.

\section{A conciliação bilateral: o ACFI Angola-Brasil}

Angola e Brasil, como já indicado, têm uma relação política emblemática e econômica significativa para ambos os países. A assimetria entre suas economias se reflete, no entanto, nessa relação, o que inclui as suas relações de investimentos: há um fluxo maior de investimentos do Brasil para Angola, que saiu do patamar de US\$ 73 milhões, em 2007, para US\$1,3 bilhões, em 20I4; sendo que o influxo de Angola para Brasil, em 2010 era de

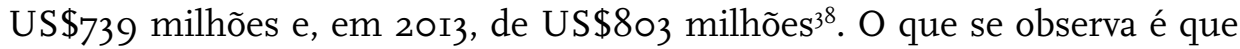
esse fluxo tem sido crescente nas duas direções. Daí o interesse e disposição da Angola e do Brasil em negociarem um acordo bilateral de investimento.

$\mathrm{O}$ acordo assinado entre Angola e Brasil, em I ${ }^{\circ}$ de abril de 20I5, assumiu a estrutura básica do ACFI - que é distinta daquela com ênfase na proteção de investimento presente nos APPIs e mesmo no Paradigma dos Investimentos de Angola. Como alertado anteriormente, a assinatura de ACFIs é recente e conta com poucos casos na história do Brasil e o acordo com Angola foi um dos primeiros a ser assinado. Isso limita as inferências que podemos fazer sobre as particularidades do ACFI assinado com Angola. Faremos um ensaio a seguir, focando em: (i) demandas já existentes para uma regulação dos investimentos estrangeiros em cada um dos países; (ii) particularidades do ACFI em relação a outros acordos assinados pelas partes no passado; e (iii) uma breve contextualização com os cinco outros acordos do gênero assinados pelo Brasil até dezembro de 2015, para análise de seus possíveis impactos.

Como linguagem geral e estrutura básica, o ACFI enfatiza a facilitação de investimentos recíprocos nas relações econômicas entre as partes e foca no discurso de fortalecimento mútuo da Angola e do Brasil. Mas, para

38 Esses são dados oficiais, sistematizados e publicados pelo Banco Central do Brasil. Para os dados sobre investimento do Brasil em Angola, v. (BACEN s.d.a). Para os dados sobre investimento de Angola no Brasil, v. (BACEN s.d.b). 
além do discurso e da forma, o ACFI Angola-Brasil também integra em suas obrigações algumas das demandas internas de cada um dos países quanto ao regime internacional de investimentos. O primeiro ponto a destacar - e que até mesmo distingue o ACFI de Angola com o Brasil de outros assinados pelo Brasil - é sobre a atribuição à legislação nacional do conceito de investimento $\left(\operatorname{artigo} 3^{\circ}\right)$. Isso é, particularmente interessante no caso de Angola, que tem alterado o conceito de investimento na legislação doméstica e que, mais do que tudo, excluiu da LIP o princípio de respeito e integral cumprimento dos tratados internacionais.

O ACFI entre Angola e Brasil também retoma os pontos mais sensíveis do regime internacional de investimentos - em especial dos APPIs - para ambos os países: (i) o tema da expropriação e (ii) o sistema de solução de controvérsias investidor-Estado. No que diz respeito à expropriação, é garantido ao estado a possibilidade expropriação, desde que seja utilidade ou interesse público, não seja discriminatória, observe o devido processo legal 39 e que, por fim, seja acompanhada por pagamento sem demora de indenização justa, adequada e efetiva, equivalente ao valor de mercado do empreendimento (artigo $9^{\circ}$ do ACFI). Diferentemente dos APPIs ratificados por Angola, o ACFI não dispõe sobre o direito do investidor de revisar a legalidade do ato de expropriação ou medida equivalente e o montante da compensação - observa-se que esta disposição também foi integrada ao Paradigma de Investimento de Angola, publicada alguns meses depois da assinatura do ACFI (artigo $5^{\circ}$ do Paradigma). Há ainda a previsão, referente à limitação constitucional brasileira, sobre a possibilidade de indenização em títulos (artigo I4.I(v) do ACFI).

Na parte relativa a solução de controvérsias, são três os pontos de destaque. O primeiro deles é sobre a valorização dos mecanismos de prevenção e consulta. O ACFI cria os pontos focais que dão apoio aos investimentos e aos investidores, inclusive para endereçar eventuais problemas quanto ao investimento no país receptor (artigo 5.I do ACFI). O ponto focal por sua vez também tem o papel de contribuir com o comitê conjunto (artigo 5.4(iii)), o qual se configura como espaço de composição entre os representantes dos estados (artigo I5). Essa estrutura, portanto, também se concilia com a restrição de Angola e Brasil quanto à cláusula investidor-estado. Isso porque garante ao investidor um espaço institucional para dialogar com o estado, mas para o caso de litígio, ao investidor fica resguardado o acesso aos tribunais nacionais

39 Nota-se que a inclusão de cláusula sobre a necessidade de observância do devido processo legal é um requisito recente nos acordos de investimento celebrados por Angola. Na verdade, ela passou a existir no Paradigma de Promoção e Proteção Recíproca de Investimentos, de 20I4, e o ACFI com o Brasil é o primeiro tratado a inserir esta exigência. 
(artigo ir.7). O terceiro ponto de destaque é, contudo, mais sensível. Trata-se do mecanismo para solução de controvérsias estado-estado. Até abril de 2015, Angola tinha por padrão em seus APPIs a possibilidade de arbitragem ${ }^{40}$, mas em agosto o Paradigma de Investimento estabeleceu a preferência pela Corte Internacional de Justiça (artigo I4.4 do Paradigma). Não se pode dizer que haja uma proibição à arbitragem internacional em Angola, constata-se apenas que a previsão do ACFI destoa daquela do Paradigma ${ }^{4 \mathrm{I}}$.

Além dessas questões pontuais, o ACFI também traz algumas preocupações específicas que foram sempre associadas às demandas de países em desenvolvimento, seja em questões temáticas seja no tocante a procedimentos, na regulação do investimento estrangeiro. A agenda temática do ACFI entre Angola e Brasil prevê programas sobre pagamentos e transferências, legislação ambiental e regulamentos técnicos, vistos de entrada no país, formação de recursos humanos e emprego de mão-de-obra local, transferência de tecnologia e cooperação em matéria de legislação setorial e intercâmbios institucionais ${ }^{42}$. As agendas temáticas permitem que as Partes negociem compromissos especiais, em listas adicionais, e outros acordos suplementares como parte do acordo principal, seja para detalhar ou expandir suas relações ${ }^{43}$. Neste sentido, o ACFI busca promover a simetria além das regras formais, incorporando a ideia de cooperação ao regime internacional de investimentos e, assim, considerando necessidades internas tanto de países importadores quanto exportadores de capital.

40 O mecanismo mais difundido nos APPIs assinados por Angola é o da arbitragem ad hoc, ou a partir das regras da UNCITRAL ou do Regulamento da Câmara de Comércio Internacional. Com exceção dos acordos com Cuba e Reino Unido, os demais preveem alternativamente a possibilidade de recorrer ao Centro Internacional para a Arbitragem de Disputas sobre Investimento (ICSID, na sigla em inglês), do Banco Mundial. Apesar de Angola não ser membro do ICSID, os APPIs que estabelecem esta cláusula indicam a possibilidade de uso do mecanismo adicional, adotado formalmente pelo Conselho Administrativo em I978 para administrar procedimentos fora do âmbito da Convenção de Washington de I965 que estabelece o ICSID. Para acesso ao conteúdo dos acordos, v. referências na nota de rodapé 29.

4I Vale ressaltar que nenhum dos ACFI chegou a definir o procedimento da arbitragem estado-estado. Essa é uma competência atribuída ao Comitê Conjunto (Artigo 4.4(vi) Angola-Brasil). Provavelmente, o procedimento deve ser estabelecido assim que os processos internos para a ratificação dos ACFIs estejam concluídos.

42 Em junho de 2014 Angola e Brasil assinaram um Protocolo sobre Facilitação de Vistos, que foi levado em conta na agenda temática sobre vistos no ACFI, conforme seu Anexo I, subparágrafo I.2(i).

43 Daniel Godinho, atual Secretário da Secretaria de Comércio Exterior (SECEX) e um dos funcionários brasileiros protagonista na formulação e na negociação dos ACFI, explica que a existência dessas agendas temáticas transformam os ACFIs, assim, em acordos dinâmicos que se desenvolvem e se aperfeiçoam em consonância com as relações de investimento entre as Partes. Entrevista Daniel Godinho, 28 de abril de 2015 (em posse dos autores). 
Alguns desses compromissos já integravam a LIP da Angola como condicionalidade para a autorização do capital estrangeiro e como obrigações legais do investidor estrangeiro. Um dos pontos mencionados acima é o da capacitação e emprego de mão-de-obra local, conhecido como processo de angolinização da mão-de-obra, com destaque para os quadros de direção e chefia (v. e.g. artigos 24(b) e 5I da Lei $\mathrm{n}^{\circ}$ I4/15 e artigo I0.3 do Paradigma). O ACFI reconhece e dialoga com estas preocupações, ao mesmo tempo em que as expande (Anexo I ao ACFI, Agendas temáticas para cooperação e facilitação).

Outra preocupação desta ordem está na autorização de medidas restritivas às transferências que sejam implementadas com vistas a salvaguardar do equilíbrio do balanço de pagamentos por uma das partes, ou para atender obrigações junto ao Fundo Monetário Internacional (artigos I4.2 e I4.3 do ACFI). Essa salvaguarda já aparecia na legislação brasileira do capital estrangeiro (artigo 28 da Lei $n^{\circ}$ 4I3I/62, alterada) e é uma preocupação comuns a Angola e Brasil que passaram historicamente por períodos de desequilíbrio econômico com severas restrições para o livre fluxo de capital.

Além disso, o segundo anexo ao acordo traz um conjunto de padrões e princípios de responsabilidade social corporativa (RSC), dentre os quais se destacam o respeito aos direitos humanos, o fortalecimento dos recursos humanos locais, a adoção de boas práticas de governança corporativa e a abstenção de ingerência na política interna dos países envolvidos. Essa preocupação já aparecia dispersa na regulação interna de Angola e Brasil, até mesmo na LIP Angolana, mas sua estruturação em um AII é inovadora. O Brasil, especificamente, não apresentava uma regulamentação com a linguagem de deveres de empresas estrangeiras nesta área ${ }^{44}$. Angola, por outro lado, a partir de seu histórico de economia planejada, com a definição necessária de deveres para os investidores, já teria elementos em sua legislação local neste sentido. A RSC como parte do texto do ACFI Angola-Brasil conferiu força em um acordo internacional a estes compromissos. Além disso, a RSC é uma disposição que ganhou nuances distintas nos ACFIs assinados pelo Brasil até o momento. Se no ACFI Angola-Brasil há uma apenas previsão genérica da obrigação (artigo Io), detalhada no Anexo, no ACFI Brasil-México e nos posteriores, as obrigações passaram a integrar o corpo principal do acordo. Contudo, a expectativa de "força de lei" se esvai no ACFI Brasil-Colômbia, especificamente quando a RSC foi excluída do mecanismo de solução de controvérsias (artigo 23 ACFI Brasil-Colômbia).

As diferenças entre os ACFI estão aparecendo com o tempo e isso é natural que ocorra, conforme o interesse das partes envolvidas. Mas isso pode

44 Até então havia apenas a coordenação sobre as Diretrizes da OCDE para Empresas Multinacionais, no âmbito do Ministério da Fazenda. 
ser uma janela para o desconhecido na estrutura do próprio ACFI Angola-Brasil, considerando a disposição sobre tratamento de nação mais favorecida (artigo II, incisos 3 e 7). Esse princípio é estendido "à defesa dos direitos de tais investidores", o que pode levar a eventual alegação de aplicação de tratamento mais favorável garantido em acordo posterior (e.g. no caso de RSC, indicado acima, abre-se margem para este tipo de interpretação).

Também no campo principiológico, vale comentar a aplicação do tratamento nacional, previsto no artigo iı.2 do ACFI Angola-Brasil. A nova LIP Angolana excluiu seu dispositivo de tratamento nacional e, indiretamente, discrimina o investimento nacional do estrangeiro. Esse poderá ser outro ponto de questionamento futuro do ACFI, caso venha a ser ratificado pelas partes, e é talvez o ponto de maior descompasse nessa nova relação jurídica entre Angola e Brasil e seus fluxos de investimentos bilaterais.

\section{Observações finais}

Este não é um artigo que nos leve a conclusões finais, mas que permite, a partir da identificação de determinantes históricos da regulamentação sobre investimentos estrangeiros, na Angola e no Brasil, avaliar o movimento de construção conjunta no ACFI e também elementos relevantes para sua implementação futura.

Na qualidade de países em desenvolvimento, é razoável que, para Angola e Brasil, a atração de capital estrangeiro seja um fator importante na promoção de suas políticas de desenvolvimento. Ambos os países evidenciam, pelas suas trajetórias regulatórias, uma conscientização maior - do que aquela nos anos i990 e início dos 2000 - acerca da viabilidade de seus compromissos no âmbito internacional face às necessidades e ambições de suas políticas públicas.

O ACFI Angola-Brasil não responde a todas as novas demandas apresentadas em cada um dos países - até porque em alguma medida ainda precisa ser regulamentado (e.g. nas previsões de arbitragem para solução de controvérsias) - mas dialoga com grande parte delas. Até onde pudermos observar, as particularidades do ACFI assinado pelo Brasil com Angola, em contraponto com aqueles assinados com outros países, indicam que, para além das demandas do Brasil, à exceção do princípio de tratamento nacional, as principais demandas de Angola quanto ao investimento estrangeiro e ao seu regime estão contempladas no acordo. O que o ACFI Angola-Brasil resguarda como particularidade é o alto grau de delegação de definições à legislação nacional. Isso requer uma atenção especial tanto do investidor privado quanto 
de agências governamentais nacionais, no ACFI e para além do ACFI.

No tocante aos movimentos da legislação doméstica de cada um dos países, o que se observa é que Angola tem modificado a sua regulamentação sobre o investimento estrangeiro, aproximadamente, a cada cinco anos, com a revisão de garantias e condicionalidades importantes. O Brasil, por seu turno, tem uma regulamentação dispersa e que está sujeita a alterações em órgãos administrativos do Poder Executivo federal. Essas definições pela legislação doméstica poderão levar a inconsistências com o ACFI, como é o caso da discriminação reconhecida pela LIP Angolana em contraponto com o princípio de trato nacional no ACFI. Portanto, no caso de aprovação do ACFI pelos processos nacionais de internalização de acordos internacionais, será aberta uma nova via necessária de interlocução para esses espaços regulatórios domésticos.

Neste sentido, o próprio acordo ainda conta com pontos relevantes a serem formatados, com destaque para as instituições que administrarão o acordo. Estão previstos para terem seu funcionamento regulamentado o Comitê Conjunto, o Ponto Focal e o próprio mecanismo de solução de controvérsias. Esses serão espaços determinantes para a efetiva implementação do acordo e sua coordenação com outros espaços nacionais. Não menos relevante será a construção da agenda temática, contínua, que dependerá de tais órgãos e sua capacidade de coordenação.

Está, portanto, apenas lançado o ACFI como espaço para efetiva coordenação entre as partes e seus homólogos nacionais, no tocante aos investimentos bilaterais, e para o desenho de instituições e agendas que atendam e respondam aos anseios comuns de desenvolvimento local e relações sinalagmáticas.

\section{REFERÊNCIAS}

Almeida, P. R. 2003. "Os investimentos estrangeiros e a legislação comercial brasileira no século XIX: retrospecto histórico.” Justiça Q História 3 (5): $73-127$.

Alves, A. G. 20I4. "As relações de investimento direto entre o Brasil e os países de seu entorno." In: Os BRICS e seus vizinhos: investimento direto estrangeiro, Alves, A.G. (org.), I3-169. Brasília: IPEA.

Angola. Lei $\mathrm{n}^{\circ} \mathrm{I} 3 / 88$, de $\mathrm{I} 6$ de julho. Diário da República, I Série, n. 29. Último acesso em dezembro de 20I5. http://www.scm.gov.ao

Angola. 2003a. Lei $\mathrm{n}^{\circ}$ II/03, de I3 de maio. Lei de bases do investimento privado. Diário da República [de Angola], Iª série, n. 37. 
Angola. 2003b. Lei $\mathrm{n}^{\circ} \mathrm{I} 7 / 03$, de 25 de julho. Sobre os incentivos fiscais e aduaneiros ao investimento privado. Diário da República [de Angola], $\mathrm{I}^{\mathrm{a}}$ série, n. 58.

Angola. 2003c. Conselho de Ministros. Decreto $n^{\circ} 44 / 03$, de 4 de julho. Extingue o Instituto de Investimento Estrangeiro e cria a Agência Nacional para o Investimento Privado, adiante abreviadamente designada por (ANIP), e aprova o seu estatuto. Diário da República [de Angola], I ${ }^{\mathrm{a}}$ série, n. 52.

Angola. 20I4. Decreto Presidencial n ${ }^{\circ}$ 22/I4, de 4 de junho. Aprova o Paradigma dos Acordos de Promoção e Protecção Recíproca de Investimentos. Diário da República [de Angola], I ${ }^{a}$ série, n. I05.

BACEN (Banco Central do Brasil). Sem data.a. Estatísticas econômicas de capitais brasileiros no exterior - 2007 a 2014. http://www4.bcb.gov.br/rex/ cbe/port/cbe.asp.

BACEN (Banco Central do Brasil). Sem data.b. Estatísticas econômicas de capitais brasileiros no País - censo 2011 a 2014 (anos-base: 2010 a 2013). Último acesso em dezembro de 20I5. http://www.bcb.gov.br/?CENSOCE.

Brasil. ı962. Diário Oficial [da] República Federativa do Brasil, Brasília, 27 set., p. I0075, passim.

Brasil. 2000. Parecer da Comissão de Relações Exteriores e Defesa Nacional [ao Projeto de Decreto Legislativo $n^{\circ} 367$ de i996]. Exposição do Deputado Luiz Gushiken. Diário da Câmara dos Deputados, Brasília, 4 mai, p. 21.693.

Brasil. 2002. Exposição de Motivos n ${ }^{\circ}$ 4OI DSF/ARC/DE-I - MIRE - PEXT EFIN, de 5 de dezembro de 2002. Diário da Câmara dos Deputados, Brasília.

Brasil. 2003. Projeto de Decreto Legislativo $\mathrm{n}^{\circ} 396$ de 2000 : substitutivo adotado pela Comissão [de Economia, Indústria e Comércio]. Diário da Câmara dos Deputados, Brasília, I2 ago.

Brasil. 2007. Lei $\mathrm{n}^{\circ}$ Iı.638, de 28 de dezembro. Altera e revoga dispositivos da Lei $n^{\circ}$ 6.404, de 15 de dezembro de 1976 , e da Lei $n^{\circ} 6.385$, de 7 de dezembro de 1976 , e estende às sociedades de grande porte disposições relativas à elaboração e divulgação de demonstrações financeiras. Diário Oficial [da] República Federativa do Brasil, Brasília, p. 2.

Brasil. 2008. Ministério de Relações Exteriores. O Brasil e os acordos de promoção e proteção de investimentos: uma perspectiva histórica [apresentação de slides]. [s.l.], set., slides I8-2I. 
Brasil. 20ıo. Conselho Monetário Nacional. Resolução $n^{\circ} 3.844$, de 23 de março de 20Io. Dispõe sobre o capital estrangeiro no País e seu registro no Banco Central do Brasil, e dá outras providências. Diário Oficial [da] República Federativa do Brasil, Brasília, artigo $\mathrm{I}^{\circ}$.

Brasil. 20II. Lei $\mathrm{n}^{\circ} \mathrm{I} 2.4 \mathrm{I} 4$, de 9 de junho. Disciplina a formação e consulta a banco de dados com informações de adimplemento, de pessoas naturais ou de pessoas jurídicas, para formação de histórico de crédito. Diário Oficial [da] República Federativa do Brasil, Brasília.

Brasil. 20I3. Lei $\mathrm{n}^{\circ} \mathrm{I2} .846$, de $\mathrm{I}^{\circ}$ de agosto. Dispõe sobre a responsabilização administrativa e civil de pessoas jurídicas pela prática de atos contra a administração pública, nacional ou estrangeira, e dá outras providencias. Diário Oficial [da] República Federativa do Brasil, Brasília.

Brasil. 20I3. Ministério do Desenvolvimento, Indústria e Comércio Exterior. "Godinho analisa momento de oportunidades no comércio exterior." 25 out. Acesso em I4 de janeiro de 20I4. http://www.mdic.gov.br/ sitio/interna/ noticia.php?area=5\&noticia $=12762$.

Brasil. 20I5a. Ministério das Relações Exteriores. "Acordo Brasil-Moçambique de Cooperação e Facilitação de Investimentos (Nota à imprensa ${ }^{\circ}$ 99)." Maputo, 30 de março. Acesso em I4 de abril de 20I5. http:// www.itamaraty. gov.br/index.php?option=com_content\&view=article\&id=85II:acordo-brasil-mocambique-de-cooperacao-e-facilitacao-de-investimentos-acfi-maputo-30-de-marco-de-20I5\&catid=42\&Itemid=28o\&lang=pt-BR.

Brasil. 20I5b. Ministério das Relações Exteriores. "Acordo Brasil-Angola de Cooperação e Facilitação de Investimentos (Nota à imprensa ${ }^{\circ}$ IO4)." Luanda, $\mathrm{I}^{\circ}$ de abril. http://www.itamaraty.gov.br/index.php?option=com_content\&view=article\&id=8520:acordo-brasil-Angola-de-cooperacao-e-facilitacao-de-investimentos-acfi-luanda-I-de-abril-de-20I5\&catid $=42 \&$ Itemid $=280 \&$ lang $=\mathrm{pt}$

Camex et al. 2009. Termo de referência: internacionalização de empresas brasileiras. Brasília. Último acesso em dezembro de 20I5. http://www. mdic.gov.br/arquivos/dwnl_I260377495.pdf

Campello, D. e L. Lemos. 20I5. "The non-ratification of bilateral investment treaties in Brazil: a story of conflict in a land of cooperation." Review of International Political Economy 22 (5): 1055-1086.

Caputo, A.C. e H. P. Melo. 2009. "A industrialização brasileira nos anos I950: uma análise da instrução II3 da SUMOC." Estudos Econômicos 39 (3): 513-38. 
CNI. 20I3. "Relatório dos investimentos brasileiros no exterior 2013: recomendações de políticas públicas para o Brasil.” Brasília. http://www. portaldaindustria.com.br/cni/publicacoes-e-estatisticas/publicacoes/20I4/OI/I,30986/relatorio-de-investimentos-brasileiros-no-exterior-20I3.html.

Dias, Bernadete de Figueiredo. 20Io. Investimentos estrangeiros no Brasil e no Direito Internacional. Curitiba: Juruá.

Ferreira, M. E. 2002. "Nacionalização e confisco do capital português na indústria transformadora de Angola (I975-1990)." Análise Social I62: 47-90.

Fonseca, R. 20I5. "Evidências empíricas na proteção do investimento direto estrangeiro em Angola e o sistema de solução de controvérsias." Trabalho de conclusão de curso, FGV Direito SP. http://bibliotecadigital.fgv.br/dspace/bitstream/handle/ı0438/ı6723/Versao\%20 Final\%20-\%2oTrabalho\%2ode\%2oConclus\%C3\%A30\%2ode\%2o curso $\% 20 \%$ E2\%80\%93\%20Rafael\%20Chaves\%2oFonseca.pdf?sequence $=3 \&$ isAllowed $=\mathrm{y}$

Gomes, Catarina Antunes. 2009. "De como o poder se produz: Angola e as suas transições." Dissertação de doutorado em sociologia, Faculdade de Economia, Universidade de Coimbra.

Gonçalves, Reinaldo. I999. "A economia política do investimento externo direto no Brasil." In: Vinte anos de política econômica, Magalhaes, J.P., Mineiro, A., Elias, L. A. (org.), 235-258. Rio de Janeiro: Contraponto.

Morosini, F. e M. R. Sanchez Badin. 20I5. "The Brazilian agreement on cooperation and facilitation of investments: a new formula for international investments agreements?" Investment Treaty News, 4 de agosto. https://www.iisd.org/itn/2015/08/04/the-brazilian-agreement-on-cooperation-and-facilitation-of-investments-acfi-a-new-formula-for-international-investment-agreements/.

Nusdeo, A. M. 2007. "A experiência do Decreto n. 57.943 como Acordo de Garantia de Investimentos entre Brasil-EUA." In: Regulamentação internacional dos investimentos: algumas lições para o Brasil, Amaral JR, A., Sanchez, M.R. (org.), 303-2I. São Paulo: Aduaneiras.

Salama, B. M. 20ıo. "Regulação cambial entre a ilegalidade e a arbitrariedade: o caso da compensação privada de créditos internacionais." Revista de Direito Bancário e do Mercado de Capitais I3 (50): I57-I84.

Scandiucci Filho, J. G. 2007. "O Brasil e os acordos bilaterais de investimentos.” In: Regulamentação internacional dos investimentos: algumas lições para o Brasil, Amaral JR, A., Sanchez, M.R. (org.), 27I-30I. São Paulo: 
Aduaneiras.

Teixeira, Carlos. 20II. "A nova constituição económica de Angola e as oportunidades de negócios e investimentos." Comunicação proferida na Faculdade de Direito da Universidade de Lisboa, 29 de março. Último acesso em dezembro de 20I5. http://www.fduan.ao/uploadfiles/pdfs/ Nova-Constituicao-EconomicadeAngola-carlostexeira.pdf

UNCTAD. 20Io. O quadro jurídico do investimento privado na República de Angola. New York/Geneva: United Nations.

UNCTAD. 20I5. World Investment Report. Geneva.

UNCTAD. Sem data. Statistic. Último acesso em dezembro de 20I5. http:// unctad.org/en/Pages/Statistics.aspx.

WTO. 20I5. WT/TPR/S/32I. Trade policy review - report by the Secretariat, I8 de Agosto. Par. 2.36, p. 26.

\section{RESUMO}

O objetivo deste artigo é contextualizar o cenário regulatório relativo a investimentos estrangeiros, na Angola e no Brasil, contrastando os movimentos divergentes desses dois países na abordagem dos acordos de investimento durante os anos I990 e início dos 2000 , e analisando como os posicionamentos de Brasil e Angola acabaram por se reconciliar com a assinatura do ACFI, no início de 2015.

\section{PALAVRAS-CHAVE:}

Investimentos Estrangeiros; Regulação; Angola; Brasil.

Recebido em 28 de junho de 2016. Aprovado em 27 de julho de 2016. 